\title{
Editorial: Why a New Journal Called Public Health Reviews?
}

\author{
Antoine Flahault, MD, PhD, ${ }^{1}$ \\ Linda Fried, MD, $\mathrm{MPH}^{2}$
}

\begin{abstract}
Most public health journals focus on new scientific articles. Public Health Reviews was established to provide reviews of important topics in public health in order to assist in translation of science into practice, in Europe and globally. Our journal is aimed at policy makers, practitioners, scientists, teachers and students of public health. By making it readily available online, we hope to reach those who cannot afford printed journals and online subscriptions in countries and regions with little or no library resources but only internet access. We hope to help in bringing context and analytic capacity to adapt health systems to successful international standards, so as to meet the challenges of change in demography, epidemiology, disease patterns and societal conditions needed to achieve the long-sought goal of health for all.
\end{abstract}

\section{EDITORIAL}

With the multiplicity of journals and internet sources in existence, one might ask, "Why a new journal called Public Health Reviews (PHR)"?

The answer is straightforward. There is a need for broad assessment of the state of public health carried out through reviews of the science and current literature to be published in a single and consistent source for analysing future policy needs in health. This is needed across Europe, in the United States, in developing countries and globally. Many lack access to library and current journal sources. Even when accessible, the available literature inundates the new student, the practitioner, and the researcher with scientific articles often expressing strikingly contradictory perspectives on very specific topics. There is a pressing need to look ahead to the emerging health needs of Europe and the larger world, taking into account all the dimensions that provide opportunities for optimising our populations' health.

\footnotetext{
${ }^{1}$ Dean, Ecole des Hautes Études en Santé Publique, Paris and Rennes, France.

${ }^{2}$ Dean, Mailman School of Public Health, Columbia University, New York.
} 
In an atmosphere where science often accumulates too quickly to be absorbed or, at times, contains contradictions or controversies, the mission of the PHR team is to bring informed, authoritative, well-reasoned interpretations that reflect a core public health philosophy and practice. We will strive to describe the state of the science, to analyse the cumulative body of evidence and its application to people in diverse locations, including those with limited or no access to libraries or even the internet. The larger aim, therefore, is to promote public health education, research, and practice with a wide international scope. Moreover, we hope to make an impact by placing emphasis on the integration of knowledge that allows science to be translated into policy and practice. We will promote interdisciplinary approaches, the diffusion of innovations and best practices, and draw attention to emerging public health issues.

This journal, which had been published for many years in Israel, was dormant for some time after the owner/publisher retired. In 2008, a proposal to bring it back to life was made, the PHR rights were purchased by Ecole des Hautes Études en Santé Publique (EHESP), and a distinguished international Editorial Board was established with institutional support from the Association of Schools of Public Health in the European Region (ASPHER), the European Public Health Association (EUPHA), Columbia University Mailman School of Public Health, University of California at Berkeley, University of North Carolina at Chapel Hill, the London School of Hygiene and Tropical Medicine and the Braun School of Public Health, Jerusalem.

The intention in relaunching this journal is not to compete with existing scientific journals, but rather to fill an underserved niche by focusing on the publication of systematic review articles addressing key public health issues. The journal will strive to be agenda-setting, offering future direction for the field of public health. To this end, our editorial policy will be to present articles that are not only descriptive, based on concrete evidence, but also anticipatory or prescriptive, describing evidence-based policy and best practices, including policy recommendations for advancing the field of public health in Europe and globally. We will endeavour to respond and contribute to European Union and US health-related agendas. Cross-cutting components will be put forward in each issue addressing concepts such as health disparities, social determinants of health, demographic shifts and changing patterns of health needs, education of the public health workforce and policy makers, and healthcare delivery systems.

From the outset, we, at PHR, decided to promote wide and easy access to our journal by publishing a limited number of issues dedicated to theme 
topics explored by invited authors. Each issue will focus on one selected theme, while being open to non-thematic reviews as well. Our first issue is entitled The New Public Health in recognition of the clear need to redefine the scope of public health in light of its rapid evolution over the past thirty years, and the need to broaden the base of professional studies in public health within the scope of civil society as much as within healthcare and medicine. The latter link is obvious and crucial, but not always an easy and comfortable partnership, with clinical and insurance-related issues dominating public discourse and determining resource allocation. A life saving new vaccine can wait for decades before being adopted in many countries, because discretionary funds are allocated to advanced medical technology in hospital centers.

We intend this journal to have a balanced view, providing opportunities for everyone, particularly Europeans, to contribute. Our primary target audience therefore includes, along with the United States, the entire European region, from Iceland to Archangelsk. Ideally, the journal will be of value to faculty and students in schools of public health, public health professionals, and health policy makers. It will be available online free of charge as well as in hard-copy for institutional libraries. It is funded completely by public sources. We would like to see this publication in regular use for teaching purposes as well as an aide to teachers and students to keep up with current trends in a dynamic, rapidly-evolving field.

We wish to promote the field of "translational science," thereby expanding the use of "best practices" following the highest ethical standards in keeping national health systems up to date. We want to reach students at the undergraduate, $\mathrm{MPH}$, and $\mathrm{PhD}$ levels with informed reviews of topics that will spread the basic concepts of public health, not only in Europe, but around the world.

We commend the pioneering work over many years of this journal in its previous form, and we hope to carry it forward with a broader agenda to a larger audience. Wish us good luck, and join us!!

Antoine Flahault, Dean, EHESP, Paris and Rennes, France; and President, ASPHER Linda Fried, Dean, Mailman SPH, Columbia University, New York, USA 